\title{
The decline of natural sciences: confronting dimi- nishing interest, fewer scientists and poorer working conditions in western countries. A comparative analysis between Spain and the United Kingdom
}

\author{
Carlos Elías \\ Universidad Carlos III de Madrid. \\ Departamento de Periodismo y Comunicación Audiovisual \\ carlos.elias@uc3m.es
}

Received: 02-11-2007

Accepted: 09-06-2008

\begin{abstract}
This study sets out to determine if the interest in and study of natural sciences is declining in western countries as scientists currently contend. Part one demonstrates how survey results reveal a decline of interest in scientific news in the EU. Part two explores the decline of interest further through examining data such as the number of students interested in scientific subjects and scientific careers. We compare data from two different countries: the UK and Spain. Within the study the UK represents the Anglo Saxon culture (traditionally more interested in science) and Spain represents the Latin culture (traditionally less interested). We conclude that in both regions there is a lack of interest in scientific subjects.
\end{abstract}

Key words: science communication, scientific policy, scientific careers.

Resumen. El declive de las ciencias naturales: determinación de la disminución del interés, del descenso de científicos y del empeoramiento de las condiciones laborales de la ciencia en los paises occidentales. Un análisis comparativo entre España y Reino Unido

Este estudio intenta esclarecer si está decayendo el interés por la ciencia y el estudio de materias científicas en los países occidentales tal y como sostienen los científicos. La primera parte demuestra como, efectivamente, el resultado de las encuestas revela que en la Unión Europea existe un declive del interés por las noticias científicas. La segunda parte explora este declive desde el punto de vista del descenso del número de alumnos matriculados en asignaturas de ciencias en secundaria y en carreras universitarias de ciencias naturales. Se comparan, sobre todo, datos de dos países muy diferentes: Reino Unido y España. De esta manera, el estudio del Reino Unido representa la cultura anglosajona (tradicionalmente, muy interesada en la ciencia) y España, la cultura latina (históricamente, menos interesada en la ciencia). Se concluye que en ambos países existe una falta de interés en los estudios de las materias científicas.

Palabras clave: comunicación científica, política científica, carrera científica. 


\section{Sumary}

Introduction

The decline in the interest for scientific

The decline in science education

The Spanish trends
The decline in scientists' working conditions

The decline in the economical conditions

Conclusion

References

\section{Introduction}

This study sets out to analyze if there is a measurable decline of interest in natural sciences in western countries as scientists contend. We first examine whether EU citizens show an increased or decreased interest in scientific news published by the mass media. We also analyse the working conditions for scientists in the USA. Finally, we compare interest in scientific subjects within two European countries: Spain and the United Kingdom. For the purposes of the study, we take Spain as a representative model of Latin culture, which includes numerous countries in Southern Europe and South America. We take the UK as a representative model of Anglo Saxon culture, which also includes the United States.

Both Spain and the UK have developed comparably rich cultures in terms of literacy and art, but are not at the same level with respect to science. In the UK the Royal Society as a scientific institution was founded in 1662, (though a group of gentlemen had been organising similar scientific discussions since 1645). The UK has therefore been a centre for scientific development from close to the beginnings of the modern science age. In comparison, Spain saw the foundation of a similar scientific institution only in 1847, a full two centuries later, a crucial time for scientific development.

One can assume that it is difficult to quantify if, for example, English literature is better or worse than Spanish literature. Who is better Shakespeare or Cervantes? Not easy to answer. But it is clear that English science is of a superior standard to Spanish science. This is not only because most of the great fathers of modern science were British: Newton, Hooke, Darwin, etc., but also in terms of raw numbers of Nobel prizes. While Great Britain has a staggering 23 laureates in Physics and 24 in Chemistry, Spain does not have a single Nobel Prize in these same natural sciences. Spain has two in the applied science of Medicine: one in 1906 and the other in 1959 to Severo Ochoa, who despite being born in Spain, worked within the USA. However, the United Kingdom has 27 laureates in Medicine. The huge gap in scientific achievement between the UK and Spain is therefore very clear. The same is evident in their overseas colonies. Even without counting the USA (the old British colony with more than two hundred scientific laureates), other former British colonies such as Australia, with a current population of 20 million, has 9 science laureates, whilst Mexico, with a population of a 100 million, has only one science laureate, who again was born in Mexico but worked in the USA. 
Despite the differences in scientific achievement between Spain and the $\mathrm{UK}$, there is something they have in common: in both of them there is a decline in the number of people interested in the natural sciences.

\section{The decline in the interest for scientific information}

In 2005 the European Commission published the Eurobarometer ${ }^{1}$ : «Europeans, science and technology», a survey among the 25 Member States of the EU. The data shows that "environmental pollution" is the news theme that gathers the most interest among Europeans, with $8 \%$ indicating that they are very interested and $49 \%$ that they are moderately interested in the topic. «New medical discovery» follows with similar rates (33\% «very interested» and 50\% "moderately interested»). The two news themes with particularly interest to our study, namely «new inventions and technologies» as well as "new scientific discoveries» receive identical scores of 30\% «very interested» and $48 \%$ «moderately interested» (table 1).

It is an important point that the news themes that have the lowest rate of interest among the European population are those that are considered as nonscientific, namely "Sports News» (respectively 26\% "very» and 42\% «moderately interested») and «Politics» (respectively 22\% "very» and 49\% «moderately interested»). From my point of view, these latter results (particularly concerning sport) appear highly surprising, largely because sports always get high TV audience ratings and shares data. Audience viewing ratings constitute direct $\&$ indisputable data, while surveys refer to intentions. In this sense, the Eurobarometer points out, «it is important to keep in mind that on such a question, respondents may want to answer in a way which is in their eyes socially acceptable». It is therefore possible that many respondents might answer that they are more interested in science than in sports for this reason.

Nevertheless, in order to prove a discernable decline of interest in science and technology themes, the most important evidence is revealed through comparison of the 2005 Eurobarometer results with those of an earlier Eurobarometer ${ }^{2}$ survey conducted in 1992 among the former 12 Members States of the European Community (table 1).

The comparison clearly shows that the proportion of persons «very interested» in the different scientific themes covered has dropped significantly since 1992. The most important decrease concerns interest in environmental pollution ( -18 points). The rate of persons very interested in new medical discoveries also decreased sharply between 1992 and 2005 (-12 points). For the interest categories «inventions and technology» and "new scientific discoveries», the «very interested» rate dropped by 5 percentage points and 8 points respectively since 1992. Respondents "not at all interested» have increased in all the issues.

1. Special Eurobarometer 224: «Europeans, Science and Technology» (2005).

2. Special Eurobarometer 38.1: «Europeans, Science and Technology» (1992). 
Table 1. Question: «Let us talk about those issues in the news which interest you. For each issue I read out please tell me if you are very interested, moderately interested or not at all interested in it».

\begin{tabular}{|c|c|c|c|c|c|c|c|c|c|}
\hline \multirow[b]{2}{*}{ Themes } & \multicolumn{3}{|c|}{ Very interested } & \multicolumn{3}{|c|}{ Moderately interested } & \multicolumn{3}{|c|}{ Not at all interested } \\
\hline & 2005 & 1992 & Diff. & 2005 & 1992 & Diff. & 2005 & 1992 & Diff. \\
\hline Environmental & & & & & & & & & \\
\hline $\begin{array}{l}\text { Pollution } \\
\text { New medical }\end{array}$ & $38 \%$ & $56 \%$ & -18 & $49 \%$ & $38 \%$ & +11 & $12 \%$ & $6 \%$ & +6 \\
\hline discoveries & $33 \%$ & $45 \%$ & -12 & $50 \%$ & $44 \%$ & +6 & $16 \%$ & $10 \%$ & +6 \\
\hline $\begin{array}{l}\text { Inventions \& } \\
\quad \text { technology }\end{array}$ & $30 \%$ & $35 \%$ & $-5 \%$ & $48 \%$ & $47 \%$ & +1 & $21 \%$ & $18 \%$ & +3 \\
\hline $\begin{array}{c}\text { New scientific } \\
\text { discoveries }\end{array}$ & $30 \%$ & $38 \%$ & -8 & $48 \%$ & $45 \%$ & +3 & $20 \%$ & $16 \%$ & +4 \\
\hline Sports news & $26 \%$ & $29 \%$ & -3 & $42 \%$ & $38 \%$ & +4 & $32 \%$ & $33 \%$ & -1 \\
\hline Politics & $22 \%$ & $28 \%$ & -6 & $49 \%$ & $52 \%$ & -3 & $29 \%$ & $20 \%$ & +9 \\
\hline
\end{tabular}

Source: Eurobarometer 38.1 (1992) and 224 (2005).

Importantly, all those respondents who answered that they are «not at all interested" in either "new inventions or technologies» or "scientific discoveries» were then asked to indicate for which reasons they are «not at all interested». The reasons given for being "not at all interested» in the above science categories in the EU-2005 were: «I don't understand»(32\%); «I do not care about it» (31\%); "I don't need it» (16\%); "I've never thought about it» (12\%); "No particular reasons» (12\%); «I have no time» (11\%); «I'm too old» (2\%); and «Others» $(2 \%)$.

From this two main reasons emerge to explain the disinterest in science and technology among the Europeans: the lack of understanding and the lack of concern. Indeed, $32 \%$ of respondents point out that they are not interested in science and technology because they do not understand it. A further $31 \%$ indicate that they simply do not care about science and technology.

When we look at the socio-demographic characteristics of the respondents, we can distinguish which social groupings are those less likely to be interested in science and technology. Among those who indicated that they "don't understand» science topics, we find predominantly groupings of persons with the lowest level of education (42\%), persons aged 55 and above and those who are retired (39\%) (table 2 ).

\section{Table 2}

\begin{tabular}{lcc}
\hline Age & I don't understand & I do not care about it \\
\hline $15-24$ & $26 \%$ & $38 \%$ \\
$25-39$ & $22 \%$ & $31 \%$ \\
$40-54$ & $29 \%$ & $30 \%$ \\
$55+$ & $39 \%$ & $31 \%$ \\
\hline
\end{tabular}

Source: Eurobarometer 224 (2005). 
Table 3

\begin{tabular}{lcc}
\hline Respondent occupation & I don't understand & I do not care about it \\
\hline Self-employed & $29 \%$ & $22 \%$ \\
Managers & $19 \%$ & $33 \%$ \\
Other white collars & $30 \%$ & $32 \%$ \\
Manual workers & $27 \%$ & $35 \%$ \\
House persons & $34 \%$ & $32 \%$ \\
Unemployed & $30 \%$ & $29 \%$ \\
Retired & $39 \%$ & $30 \%$ \\
Students & $20 \%$ & $37 \%$ \\
\hline
\end{tabular}

Source: Eurobarometer 224 (2005).

However, the crucial point is that in those who answered that they «don't care» about science $\&$ technology topics, the youngest aged people $(38 \%)$ and students (37\%) featured strongest. For these social groupings the lack of interest is not due to lack of understanding or education, rather I suggest it is a problem of communication and image.

As indicated in the table shown below (table 3), students are the group possessing one of the best understandings of science, but at the same time they have the least care for it (37\%). I suggest that this is a symptom of a declining interest in and image of science.

According to Eurobarometer data (2005) from Spain and the United Kingdom, we find that the British are twice as interested in science and technology than the Spanish (table 4). This would indicate that there are large differences of influence acting upon the respondents who answered they were not at all interested in «new invention" and "new discoveries» between the two countries.

The results are consistent with the fact that in the UK science and technology used to be more important than in Spain not only in the educational system but also in terms of mass media coverage. They affirm that it is important not only how science is taught, but also how science is communicated and the image of scientists in the public eye. In many respects the data could be considered an important contrast of two cultural archetypes: Latin culture, in which science is not as highly developed as other disciplines and Anglo Saxon countries, in which science has a long-standing cultural tradition of the highest quality, and has always played an important societal role.

However, if we look at the decrease in interest in science in recent years, we see a very similar trend in Spain and the UK. A comparison of results from

Table 4

\begin{tabular}{lcc}
\hline Country & I don't understand & I do not care about it \\
\hline Spain & $43 \%$ & $38 \%$ \\
UK & $27 \%$ & $15 \%$
\end{tabular}

Source: Eurobarometer 224 (2005). 


\section{Table 5}

\begin{tabular}{lccc}
\hline Spain «very interested» & $\mathbf{1 9 9 2}$ & $\mathbf{2 0 0 5}$ & Diff. \\
\hline New scientific discoveries & $37 \%$ & $25 \%$ & -12 \\
New inventions and technologies & $33 \%$ & $27 \%$ & -6 \\
\hline
\end{tabular}

Source: Eurobarometer 38.1 (1992) and 224 (2005).

\section{Table 6}

\begin{tabular}{llll}
\hline United Kingdom «very interested» & 1992 & 2005 & Diff. \\
\hline New scientific discoveries & $41 \%$ & $33 \%$ & -8 \\
New inventions and technologies & $39 \%$ & $33 \%$ & -6 \\
\hline
\end{tabular}

Source: Eurobarometer 38.1 (1992) and 224 (2005).

the 1992 and 2005 Eurobarometer surveys, reveals in both countries a significant fall in numbers of people who answered "very interested» in scientific items (tables 5 and 6). Both countries, despite different levels of interest in 1992 (in UK much higher interest than in Spain), are now recording similar low rates of people «very interested»; so it is a worrying trend for Spain and the UK alike.

\section{The decline in science education}

We are reporting a significant decline of interest in the sciences but so far only in accordance with the surveys database. For a more reliable picture, more direct data is required, so here we examine whether a similar trend of decline is seen in the number of students who choose scientific subjects and careers. In 2006 Sussex University announced to shut down its high- ranking chemistry department, the proud source of three Nobel laureates. Scientists reacted angrily to the announcement but Sussex University's authorities confirmed the plans to concentrate in other areas, including English, history and media studies.

It was the latest in a long list of closures indicative of the weakening state of chemistry education in the UK universities: King's College London closes chemistry department (2004); University of Wales Swansea stops taking in new chemistry undergraduates (2004); Queen Mary, University of London, merges chemistry with biology (2005); University of Dundee closes division of physical and inorganic chemistry (2005) and University of Exeter merges reduced chemistry department into biological sciences (2005).

According to The Observer (12 March 2006: 12): «Financial pressures and the shift of popularity towards less traditional subjects such as media studies have been blamed». In a statement to staff, the vice-chancellor at Sussex University said chemistry was «a difficult recruitment area» at present times. 
Unfortunately, this statement is the truth. According to the Higher Education Statistics Agency ${ }^{3}$, the number of UK students in the first year of fulltime and part time degrees courses increased by $11 \%$ between 1995-96 and 2001-02. Although there was a rise over this period of 53\% in the number of computer science courses, and an increase of $22 \%$ in those studying biological sciences, there were drops of $8 \%$ in engineering and technology and $20 \%$ in the Physical Sciences. In chemistry, numbers fell by $31 \%$ and in physics by $13 \%$.

In contrast, the number of students registered in media studies rose from 6,888 in $1995-96$ to 15,905 in 2001-02. So this subject saw a recruitment rise of $43 \%$. Journalism increased by $29.6 \%$. However, the crucial point is that in 2004-2005 the number of students in media studies increased to 26,685 .

In this academic year 2004-05, the numbers of students registered in UK universities were as follows: 18,520 in chemistry; physics $(14,610)$ and biology $(26,290)$. In media studies there were 26,685 registered, more than in Biology even, making the year 2004-2005 the first year in which there were more students in media studies than in the traditional natural sciences. In journalism also there were 7,570 registered.

UK Secondary School education shows similarly worrying trends. According to figures compiled by Institute of Physics ${ }^{4}$, the total number of A-level entries between 1991 and 2003 across all subjects in England, Wales and Northern Ireland increased by $7.4 \%$. Entries in biology rose by $11.0 \%$ over this period, but there were falls of $18.7 \%$ in chemistry, $25.4 \%$ in mathematics, and $29.6 \%$ in physics. The three sciences and mathematics accounted for $30.0 \%$ of all Alevel entries in 1993, but only 23.2\% of entries in 2003.

The British newspaper The Observer (9-July-2006:25) printed an analysis written by Boris Johnson: «In the last eight years, 30 per cent of physics departments have closed and chemistry is in similar straits. The universities will say that this is partly to do with the funding formula, which does not cover the extra cost of teaching science, but we all know that the real problem is in the schools». According to Johnson «the figures are terrifying». So, in the 20 years from 1985 to 2005 , the overall number of entries at A-level rose by 100,000, from about 680,000 to about 780,000. Yet maths fell from 71,608 to 58,830. Physics A-levels slumped from 46,606 to 28,119. Chemistry fell from 40,337 to 38,850 . «There are some London boroughs — writes Johnson — where further maths is virtually extinct».

From the point of view of Sir Alistair MacFarlane, chair of the Royal Society education committee, «these downward trends will inflict huge damage on the UK if not reversed, adversely affecting prosperity and the quality of life in the UK».

3. These data are available in Higher Education Statistics Agency web site: http://www.hesa.ac.uk/ in statistics on line: students data, "Subject of Study».

4. These data are also available in Institute of Physics web site: http://www.iop.org/, in Physic Education Policy. The Institute of Physics is a leading international scientific society over 37.000 members which promotes the advancement of Physics. 


\section{The Spanish trends}

In Spain there is a similar trend to that in the UK concerning the lack of interest from youth in the study of natural sciences. The Spanish Foundation of Science $\&$ Technology published a survey with the entries in naturals sciences from 1988-89 to 2000-01 (Elías, 2006). The first conclusion is that there was a fall of $6.25 \%$ in numbers of entries in the A-level scientific options. However, the situation is more dramatic in the universities.

In contrast to the UK, in Spain there was a fall of $4.4 \%$ in the total number of university entries, due to the fall in the Spanish birth rate and the lack of overseas students interested in registering in Spanish universities. From 1988-89 to 2000-01 entries in scientific careers fell $1.42 \%$. Maybe this does not sound like much. However, there is a significant fall in the number of those choosing to study classical natural sciences. Data from the Spanish Education Office from 2000-2004 proves physics fell by $12 \%$. Chemistry fell by $18 \%$ (from 30,744 to 25,171 ). So that means a fall of 5.570 students in only four years. Mathematics dropped by $20 \%$, and Biology only fell $7.9 \%$.

In contrast to this, and in a similar trend to UK, Journalism has risen $4.4 \%$ but actually the star is Cinema \& TV studies, which has risen $13 \%$. Data from the academic year 2003/2004 shows the following number of students registered: chemistry $(25,171)$; Physics $(10,923)$; Mathematics $(8,266)$; Cinema \& TV studies $(11,266)$ and Journalism $(16,656)$. Data from Italy -a country with similar cultural parameters to Spain- shows the following numbers of students registered: in Physics \& Maths $(4,126)$; in Chemistry $(2,628)$ and in Media Studies $(54,000)$.

\section{The decline in scientists' working conditions}

In 2001 Freeman et al. published a study in Science in which they showed how scientists' working conditions have declined during the last ten years (Freeman et al., 2001). Their research focused on bioscience, but some of their results can be extended to the whole of the natural sciences. Their analysis suggests an inconsistency between the promise of scientific career prospects and how difficult it is in reality to get a good job as scientist during the present time.

According to Lazear and Rosen (1981), research in the natural sciences fits a tournament economic structure. A tournament offers participants the chance of winning a big prize — an independent research career, tenure, a named chair, scientific renown, awards- through competition. It fosters intense competition by amplifying small differences in productivity into large differences in recognition and reward. Well-structured tournaments stimulate competition. Because the differences in rewards exceed the differences in output, there is a disproportionate incentive to "win». Victory may result from being marginally better than competitors, e.g., completing a key experiment a week earlier (Freeman et al., 2001). 
But according to Freeman et al. this configuration puts enormous competitive pressure on Principal Investigators (PIs), because the slightest edge can make the difference between success and failure. Many PIs interviewed by Freeman et al in their study respond to the possibility of being «scooped» by working long hours. Nearly one-third of PhD biological scientists work 60 or more hours per week compared with $24 \%$ of other PhD scientists. Bioscience PhD's aged 35 to 44 work about 50 hours per week. The long hours especially impact those balancing career and family. Among PhD biologists without children, women work more hours than men, but among those with children, women work significantly fewer hours than men.

The decrease in hours worked by mothers damages career progression in the biosciences because of the rapid progression of the field, one indicator of which is the median number of years of journal citation (citation half-life). Biosciences have the shortest citation half-life among all sciences, making it difficult to pause from or reduce work and return to the same career trajectory as before (Preston, 2000).

Data from the National Science Foundation documents the link between work hours and scientific success. Between 1990 and 1995, bioscientists published 6.7 papers per year compared with 4.7 papers for scientists in other fields. In biosciences, 5 hours of work per week is associated with one additional publication, and each publication corresponds to approximately $0.9 \%$ higher salary. Bioscientists who work more hours publish more, and those who publish more, earn more.

Ideally, tournament job markets are socially efficient, inducing high productivity from all participants. However, tournaments can also produce perverse outcomes. The tournament model creates the incentive to publish quickly and to recruit as many postdoctoral fellows as possible, irrespective of the personal values of their training.

One PI interviewed by Freeman et al. for their study said: «If I have three postdocs and we work all the time, I have bigger chance of getting my results out first than if I have two postdocs and I take off weekends». This is one of the crucial points: at the present time science cannot be predominantly an intellectual work but rather a mechanical repetitive job, e.g. Dolly the sheep was a result of repetitive experiments more than a new scientific discovery or idea.

\section{The decline in the economical conditions}

Senior scientists may recognize that they and their students should take more time for their personal lives, but they adapt to their incentives. Scientists work hard, but ... does it mean that at least scientists earn a lot of money? No. PIs interviewed by Freeman recognize that graduate students and postdocs often struggle economically. But as long as cheap postdoc or graduate student labour is available, PIs will use them as their primary labour input. For this reason senior scientists are so worried about the decline in scientific careers. 
If encouraging graduate students and postdocs to narrowly specialize helps PIs win the research tournament, this will occur even if alternative forms of training, or leaving the lab sooner, might better serve the students and postdocs (Freeman et al., 2001).

In the same vein, if PIs cannot attract postdoctoral fellows from the United States or institutions cannot attract qualified graduate students, they widen their search geographically or lower admission standards.

Other problem is that the long duration of graduate and postgraduate training and low rate of pay gives scientists lower lifetime income than people in other careers that require high levels of education. According to Freeman many scientists do not obtain their first salary until their mid-30s. This is new, as this was not the case in the 60s, 70 s or 80 s. So from my point of view, this tournament structure that generates good research by employing idealistic young graduate students and postdoctoral fellows at low cost is further evidence of the decline of science.

The worrisome reality is that scientists and engineers aren't well paid, considering their skills and — specially for $\mathrm{PhD}$ — the time required to gain a degree. This means the job market is too weak to attract increasing numbers of students in western countries.

As Robert J. Samuelson (2005) reported at The Washington Post from 1990 to 2000 , average income for engineering $\mathrm{PhDs}$ increased from $\$ 65,000$ to $\$ 91,000$, up 41 percent; PhDs in natural sciences (physics, chemistry) rose from $\$ 56,000$ to $\$ 73,000$, up 30 percent. Meanwhile, average doctors' incomes increased from $\$ 99,000$ to $\$ 156,000$, up 58 percent; and lawyers went from $\$ 77,000$ to $\$ 115,000$, up 49 percent.

The true situation may be worse. Next to other elites, scientific and engineering PhDs fare poorly. According to Samuelson the $891 \mathrm{MBA}$ recipients of the Harvard Business School's class of 2005, at an average age of 27, earn a median starting salary of $\$ 100,000$.

These dramatic economic conditions for scientists are other sign of decline. Clever young people love money and free time as well as being interested in a good profession. This could explain some data, for example why in 1975, the United States produced more science graduates and more engineering and scientific PhDs than Europe and more than three times as many as in all of Asia. According to the National Science Foundation, in 2001 China graduated 220,000 engineers, compared to about 60,000 for the United States.

\section{Conclusion}

All the data mentioned above very often appears in the mass media. In contrast, a study concluding that the proportion of Britain's top journalists who were privately educated has risen to 54 of the current top 100, up from 49 twenty years ago, has had very little media coverage. One of the reasons for this trend, according to Howard Davies, director of London School of Economics, «may be the recruitment pattern of media organisations». «Increasingly, writes Davies, 
they expect graduates to take unpaid internships if they whish to get their feet on the first rung of the ladder. That skews their recruitment towards the scions of better-off families, who can afford to work for nothing for a while (Davies, 2006)». So that means journalists' working conditions are even worse than scientific ones, because scientists can get badly paid but journalists are not paid at all. This is yet further indication that many people choose media studies because of glamour incentive and not because of mass media working expectations. Nevertheless the working conditions of journalists barely appears in the mass media because its own credibility could be threatened.

When Samuelson reports in The Washington Post about scientists' low salaries compared with other professionals, or when The Observer writes about why academic authorities are going to shut down the Chemistry Department at Sussex University or publishes a report about a strike of young scientists complaining about their working conditions, the idea we are spreading among the public is that Science is something in decline. And of course, nobody wants to enrol in a field that is in decline. Everybody prefers to enter a field enjoying success.

\section{References}

DAVIES, H. (2006). «Why investment banks appeal to top graduates». The Independent, July $13^{\text {th }}$.

ELÍAS, C. (2006). «Influencia de los medios de comunicación en la elección cienciasletras en bachillerato y universidad. El caso español: análisis del periodo 19882001». Estudios sobre el mensaje periodístico, 12: 253-274.

Freeman, R.; Weinstein, E.; Marincola, E.; Rosenabaun, J. and Solomon, F. (2001). "Competition and Careers in Biosciences». Science, 294: 2293-2294.

LAZEAR, E. and ROSEN, S (1981). «Rank-Order Tournaments as Optimum Labor Contracts». Journal of Political Economy, 89: 841-64.

Preston, A. (2000). «Do differences in Rates of Skill Depreciation Across Scientific Fields Impact Labour Market Outcomes?». Haverford College, cited by Freeman et al.

Samuelson, R. J. (2005). «It's Not a Science Gap (Yet)». The Washington Post, August $10^{\text {th }}$.

Special Eurobarometer 224: «Europeans, Science and Technology» (2005).

Special Eurobarometer 38.1: «Europeans, Science and Technology» (1992). 